\title{
Marketing resource management: Making the most of investments through more efficient DAM, marketing operations and marketing- related business processes
}

\begin{abstract}
Scott Allan
earned his MBA from Boston University and has extensive experience in marketing at Fortune 500 companies. He has in-depth knowledge of how information technology efforts can increase the performance of marketing organizations. At IBM, Allan managed a 13-city tour launching IBM Lotus Notes and Domino. Part of the project included a multimilliondollar demand-generation effort that resulted in thousands of leads. At EMC Corporation, he launched some of the company's first successful channel marketing programs designed to help channel partners run their own integrated marketing campaigns.
\end{abstract}

Keywords: marketing resource management (MRM), marketing operations management, enterprise marketing management, digital asset management (DAM), multi-channel publishing

Abstract For many companies, the marketing department is the last business function to use information technology to automate processes. Without a comprehensive platform approach, applications designed for marketing departments are really point solutions. Some focus on tracking the results of marketing activities such as printed direct mail. Some focus on collaboration. Others focus on web-based marketing. In the past few years, senior marketing executives have taken a step back and realized that ad-hoc point solutions aren't the answer. What they need is a longterm, integrated IT strategy designed for marketing: marketing resource management (MRM).

\section{THE HISTORICAL PROBLEM}

IT trends come and go, and the best decision makers see through hype cycles and focus on the ultimate long-term value of any solution or long-term IT strategy. For many companies, the marketing department is the last business unit to be automated using information technology. Manufacturing was first with enterprise resource planning (ERP) and then a wave of acronyms followed including supply chain management (SCM), customer relationship management (CRM) and many others. The needs of marketing departments, however, typically got lost under the enterprise content management (ECM) umbrella and the hype surrounding new regulatory requirements such as Sarbanes-Oxley.

Instead of a comprehensive platform approach, software applications designed for marketing departments have been delivered in the form of point solutions. Some, for example, have focused on tracking the results of marketing 
activities such as printed direct mail, while others have focused on collaboration or on web-based marketing. No software application has presented a comprehensive solution that serves all the needs of marketing departments.

In the last few years, senior marketing executives have taken a step back and realized ad hoc point solutions are not the answer. What they need is a long-term, integrated IT strategy designed for marketing.

\section{AN EMERGING SOLUTION}

This is where marketing resource management (MRM), also called marketing operations management or enterprise marketing management, comes in. MRM is the framework for creating an IT strategy specific to the challenges marketing departments face today.

MRM is not a turnkey solution but rather a discipline for addressing the unique IT challenges of marketing in a methodical way. It helps managers find ways to cut costs, enables better utilization of existing marketing assets,

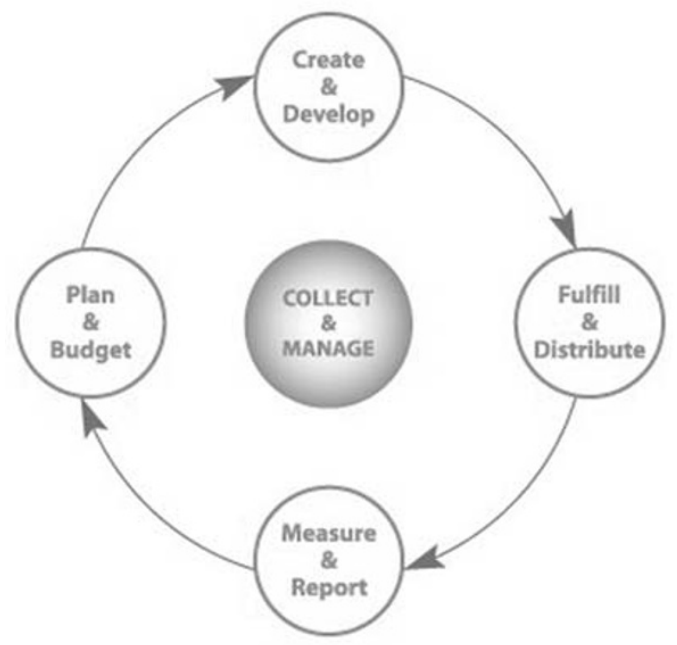

Figure 1: Marketing resource management increases collaboration and makes marketing personnel more productive.

MRM looks at the challenges of marketing in five areas (Figure 1):

1. Planning and budgeting marketing activities.

2. Collecting and managing marketing content.

3. Creating and developing marketing content.

4. Fulfilling and distributing marketing content.

5. Measuring and reporting on the status of marketing content, campaigns and initiatives.

\section{PLAN AND BUDGET}

Ask any marketing executive how they create and manage marketing plans and budgets and one is likely to get a myriad of answers. Marketing executives who actually write down a plan most likely save it on the local drive of a PC somewhere. But is this plan the most up to date? Are the right people accessing, reviewing and commenting on it - and the right version of it? When the time comes to write the next marketing plan, are older versions easily accessible, or is the marketing manager reinventing the wheel each time?

If you are working with an MRM company and tracking the results of your marketing campaigns, you may need to connect your enterprise systems with the metadata for your digital assets. For example, after implementing a printed direct mail campaign, you need to tie results obtained by the MRM system and financial systems to all the digital assets involved in the campaign automatically. With the right solution, you can keep track of your marketing plans and digital assets, share them 
effectively and tie them to the results of your campaigns.

The benefit of centrally managing budgets and creative assets relates to tracking patterns over time. For example, many companies have ongoing printed direct mail campaigns. If a marketing manager wanted to compare the difference in response rates between postcards that used stock photography and postcards that used newly commissioned photography, compiling such a report could be a lengthy, painstaking process unless all of the related information is centrally located. These types of questions often go unanswered because few companies have the necessary data to do this analysis. Such information, however, could affect decisions about future postcards that could lead to significant savings or significant increases in revenue.

Part of any good MRM strategy, therefore, is the ability to store, track and manage your marketing plans, and keep all of the digital assets associated with the plan connected, not just to the plan but also to the right people. This way, you can track versions, edit history and create customizable metadata about your marketing plans to tell users where the plan is in its lifecycle so you can make adjustments and take action. In our photography example, the marketing manager could increase the return on the project by using the photography with a higher response rate.

The first place to start is with a digital asset management (DAM) system that marcom departments can use to centralize and control access to all marketing-related content. The system should combine advanced, enterpriselevel DAM with workflow capabilities, version control, web-enabled access and much more.

For example, Demco, the leading business-to-business direct marketer for libraries and schools, implemented a content management solution that gives the company easily accessible data; organizes storage and retrieval of images, pages and documents; and provides consolidated record-keeping and attribute capacities for the organization's print and web groups. Demco increased the number of pages produced by more than 30 per cent and reduced overtime by 40 per cent. In addition, by internalizing image, file and proofing processes, the company expects to realize a 40 per cent saving by the end of 2005 .

\section{COLLECT AND MANAGE}

DAM systems are critical to any successful MRM strategy. They allow companies to manage marketing-related assets such as photography, JPEG, EPS, QuarkXPress files and other types of content centrally. Centralizing assets will make them easy to find and reuse and enable access control relative to people both inside and outside the company. Users need to securely "check-in" and "check-out" assets making them visible to everyone working on a project. As the asset database grows larger, users need to run complex queries, conduct full-text searches, and schedule work for other team members using advanced workflows.

For example, the creative services team at Lenox Collections, a direct response company, needed a way to locate image files and layouts quickly, without wasting time sifting through almost a terabyte of data. By implementing a content management 
system, they reduced search and retrieval time by $80-90$ per cent and gained tighter control over the accuracy of information in the organization. Now, ten other departments within Lenox Collections are looking at implementing a similar system.

In addition to the digital assets themselves, you may need to store additional information about the assets to make it easy for users to find what they need. Just as libraries store information about books in a card catalog or computer system, a DAM system can store information known as "metadata." The right system can automatically gather data about an asset and store it in the asset's attributes file. This could include file type, size, last modified date and any file type-specific information, such as resolution for image files or word count for text files. Alternatively, you can customize metadata so that each type of asset has its own set of custom attributes.

Surprisingly, many companies still store their digital assets on file servers or DVDs using cryptic naming conventions. Worse still, graphic designers store the digital files on their local hard drives, which can lead to total data loss if a hard drive fails. Under such conditions, the knowledge of how to find the right file, at the right time, for the right person often resides with just a few people.

The page layout artists, for example, can easily find the digital asset they need by searching on a variety of information related to the file, such as the name of the file, date, file type or job number. Once the designer finds the file, they can simply drag and drop it into the layout directly from the DAM system. This might seem like a simple task, but compare the designer who works at Lenox with one who works at a company where images are stored on CDs or DVDs. Finding a file stored somewhere within two years' worth of DVDs can be a long process and the knowledge of naming conventions often resides with just a few people. Should the relevant person leave the company, finding the file can be even more timeconsuming.

Companies can start out by implementing a simple departmental solution and as needs grow, deploy a more advanced solution with features such as workflow automation, storage and client access.

\section{CREATE AND DEVELOP}

Time is critical when creating marketing material. With the onslaught of multichannel and media-independent publishing, marketing departments' demand for speed and agility - and the ability to create all kinds of output has grown exponentially. A powerful and effective MRM solution also enables multi-channel and media-independent publishing so you can reuse content easily.

\section{MULTI-CHANNEL PUBLISHING}

Multi-channel publishing cuts production time and empowers your marketing and creative staff to be more productive. Designers often create materials for print and web, all based on the same content.

You need a convenient and intuitive way to create and store mediaindependent content. You need an automated process that extracts content from documents and stores it in an Extensible Markup Language (XML) format. You can then use that content 
with HTML templates to create dynamic web pages. You may need to place XML content in a document automatically for print, HTML or PDF output - in essence, an easier and faster way to create multi-channel content.

For example, one Quark customer who produces a wide range of printed publications is using XML to publish content simultaneously to QuarkXPress documents and to its website. The company automated what was previously a manual publishing process requiring 6-10 days. By implementing an XML-based solution to automate the process, the entire procedure now requires less than a day — including proofing. The company also automated the process to convert the highresolution pictures used in their QuarkXPress projects to low-resolution pictures for use on the web. This process now takes around 20 minutes and does not require any staff resources. In addition, the workflow now connects the sales, publishing and web departments and has improved the consistency of the information used for 70-100 products monthly.

DAM systems can also automatically convert files into different formats. For example, you might want to convert all the pictures in your QuarkXPress files to low resolution JPEG files automatically when you check in the QuarkXPress layout. Such automated logic can be an important part of any DAM system and a huge time-saver for designers and other users of the system who have multi-channel needs.

\section{REVIEW MANAGEMENT}

Creating and developing can also mean lengthy review and approval cycles that can often make "time-to-production" unacceptable. Marketing departments and creative agencies need tools to help shorten review cycles while including everyone necessary - even those who do not have graphic design skills.

Today, unfortunately, most people are still converting files to PDF and manually making file markups for the creative professional to consolidate. It is an unproductive method to get final approval and can often lead to costly mistakes. An MRM strategy should include tools to help users become more productive and more collaborative in their review and approval work patterns.

What if you had a tool that enabled online review of all your documents QuarkXPress, JPEG, EPS or even Flash and live websites - so that users could send their co-workers a link to review various types of files? Participants in the review cycle would not need to know the originating applications or have that application installed on their computer. What if you had an electronic mark-up tool that replaced the usual pens and Post-it notes so that multiple users could comment on the document or image simultaneously and see each other's comments instantly?

For example, one Quark customer eliminated tedious review cycles and dramatically improved review turnarounds, tracking and accuracy of changes by implementing a completely digital review process. Now, they no longer have to waste time producing and distributing multiple hard copies, tracking down documents to move them along in the review process, and collating comments by hand. Reviewers can simultaneously review and annotate files without having to convert them to PDF, which improves production 
quality, speeds turnaround times and frees account managers for more customer-oriented tasks.

\section{BRAND MANAGEMENT}

Creating and developing content revolves around controlling a company's brand. Marketing departments face the vexing challenge of creating more content and executing more campaigns and programs with fewer resources. Proper control of brand elements such as logos, layouts, graphical treatments and other guidelines is critical to avoid weakening the brand with inconsistent execution. You can miss valuable opportunities, however, if other interested groups such as field marketing, business partners and others with a valid need to use branded materials are not leveraging the brand effectively.

Making matters more complicated is the need for a variable component to handle most types of materials. For example, a joint marketing brochure might need an area for partners to place their logo and contact information but the business partner should not be able to change the layout, certain copy or other branded elements on the brochure. An effective MRM strategy should empower certain users to create customized marketing material that also meets the brand and style guidelines set forth by creative directors.

What if you could create web-based, template-driven content that accommodates variable components? This is especially useful for personalizing marketing content and for one-to-one marketing strategies. Any templates would include branded elements that are "locked" so that the user can only change what the designer has designated as a variable ensuring brand integrity and tone. In addition, the user can output to multiple formats such as QuarkXPress, PDF, JPEG and other formats.

For example, New England Business Service Inc. (NEBS), a leading businessto-business enterprise supplies more than 4,300 clients in the USA, Canada, UK and France with a variety of business products and services - all designed and priced to meet the needs of a small business. Much of the growth NEBS experienced over the past decade was based on acquisition, resulting in nearly a dozen different production systems and workflows to produce its various marketing collateral and handle product sales. Although the organization's existing workflows worked well, it cost $\$ 1 \mathrm{~m}$ a year to maintain the legacy composition system. By implementing an integrated solution, the company is now able to create design-rich document templates and store them on a webaccessed server. Whether system users are staff members connected to a company's intranet or customers dispersed around the globe, everyone can access the templates through a web browser, add their own content to the templates and manipulate predefined content. All of this has resulted in a profoundly positive effect on the speed, quality and accessibility of producing professional publications and other printed products.

\section{FULFILL AND DISTRIBUTE}

Marketing resource management can also address the challenges associated with the distribution of marketing content. Collaboration is key during the "create and develop" process but agencies and marketing departments 
always need secure ways to share and distribute content before, during and after it is developed. In addition, the collaborative process needs to be flexible so the agency can easily expand or limit the pool of participants in marketing operations. This way, you can bring customers, business partners, agencies or any other custom-defined group into your processes.

\section{PRINTING: ON-DEMAND AND PERSONALIZED}

Apart from flexible access to digital content through various client options, another key aspect to "fulfill and distribute" is printing. According to market research firm CAP Ventures Inc., more than one-third of content and documents no longer have print as the primary final output, and nearly 40 per cent of content has moved to an electronic-first method of delivery. Most MRM strategies will include a print component, and today printing over the web is especially important for personalization and print-on-demand solutions.

For example, DeskNet Inc. uses Quark Dynamic Document Server to help financial services companies deliver on the promise of the convergence between compliance and marketing communications - from personalized marketing kits, institutional reports and education materials to mass-market communications and regulatory publishing. Uniting these diverse information flows ensures brand fidelity and increased customer retention while satisfying corporate-wide regulatory compliance at lower costs.

Another example is Cierant Corporation. Cierant uses an on-demand publishing solution to offer their customers a solution called Marcom Center, a state-of-the-art component of their eCommUNIQUÉ solution. Marcom Center gives marketers the freedom and flexibility to customize their own documents online. Using industry-standard QuarkXPress templates, customers have complete freedom in developing personalized materials. Knowledge of QuarkXPress means customers already know how to use Marcom Center. In addition, the familiar interface ensures quick set-up and simplifies system maintenance. With Marcom Center, retailers, dealers, distributors and sales offices have the ability to create and order brochures, direct mailers, fliers, posters, ads and nearly every other kind of print collateral using their own computer.

\section{MEASURE AND REPORT}

Effectively measuring and reporting on the results of marketing campaigns has been one of the most challenging aspects of MRM. A complete MRM strategy connects marketing analytics with DAM solutions; allows marketers to manage marketing initiatives across the entire marketing supply chain and optimize core functions; and includes information management, production, operations and team communication.

MRM will ensure results that are applicable to the entire marketing discipline and not solely on areas like direct marketing. When you combine measurement and reporting capabilities with campaign and digital asset management, marketing staff benefit from the advanced segmentation and campaign execution functionality, in addition to the solution's multi-channel publishing capabilities.

For example, one Quark customer was 
able to ignite renewed interest in its gourmet food club membership - a program that brought the winery an annual sales average of $\$ 1,000$ per member - by taking advantage of the data it had on each customer's wine tastes. By crafting a personalized catalog for each customer based on his or her tastes and sending it to members, 90 per cent of the winery's former members who returned to the gourmet food club placed orders adding up to $\$ 225,000$ in incremental sales. By deploying this realtime target marketing (RTTM) campaign, the winery not only increased sales, but it also gained a method for test-marketing new products and changing pricing and other information on the fly.

Another example is BrandWizard Technologies. BrandWizard uses Quark Dynamic Document Server to create personalized collateral services for their clients. Channel marketing organizations use standard corporate marketing templates for advertising, direct mail, posters and other creative assets, and choose photography and copy to make the content more relevant for the customers in their district. On behalf of the parent company, the BrandWizard solution collects statistics on which marketing templates the channel uses most often. Corporate marketing at the parent company can then make strategic changes to the template content and design based on that information.

\section{RETURN ON INVESTMENT}

The equation for measuring the return on investment (ROI) for any MRM initiative will be different for every company because the bottlenecks at one company might not exist at another. For example, an advertising agency with hundreds of clients might need an online review and approval process that ties in to their DAM system, and that could be the deciding factor in the selection of a vendor.

Another company with more than 100 QuarkXPress licenses might need ways to help their designers find and use files efficiently and in as few steps as possible. For that company, the ability for the designer to drag and drop from the DAM system directly into QuarkXPress and other design applications might be a key selling point.

At yet another company the decision point might rely with IT management. Advanced storage capabilities could be on the list of requirements if you expect content growth rates to be extremely high. Alternatively, integration capabilities could be another point for measuring ROI. One question many companies ask is, how does the MRM system connect to an existing internal database or other type of data source representing a current multi-year investment that is critical to the operation?

The first decision any project manager must make when trying to measure ROI for an MRM initiative is determining what the system will measure. Is it the time it takes to find an image from one of the marketing campaigns from last year? Is it the time it takes to review and approve a printed direct marketing concept? Or is it the time it takes to generate a client revenue report that contains information about how many QuarkXPress files you created for the client and what pictures you used in those layouts? Find out from the system users what you should measure and agree on a goal to work 
towards as you pilot test or implement the system.

\section{START THE JOURNEY}

Many companies are planning an IT strategy for marketing because they are under more pressure than ever before to justify marketing expenditures. There are many ways to start building an efficient operation to address all five areas of marketing, ie (1) planning and budgeting marketing activities; (2) collecting and managing marketing content; (3) creating and developing marketing content; (4) fulfilling and distributing marketing content; and (5) measuring and reporting.

DAM, for example, is just one step in the journey to MRM. For many companies, however, it is the first step that leads to building capabilities around DAM to address each of the five areas of MRM. If your creative staff are still saving content on file servers, wasting time looking for files or recreating content from scratch, then a DAM system could provide an immediate ROI. When evaluating a DAM system or developing an asset management strategy, some of the criteria to consider include:

- Can it provide flexible ways to track marketing plans and keep them connected to related marketing assets?

- Can it store them in a "collection" and connect them to all the digital assets associated with that plan so users can easily find everything?

- Can it provide ways to track versions, edit history and create customizable metadata about marketing plans that tell users where the plan is in its lifecycle?
- Who will be the executive sponsor and who will be the end-user champion for the initiative?

- Can the system leverage current IT investments by integrating various data sources and other information?

As trends in MRM continue and convergence of technologies take hold, embarking on a strategy for marketing automation can begin with centralizing digital content and other marketingrelated assets. More importantly, however, implementing an MRM plan can introduce automation to your marketing department and make your marketing staff more efficient and better able to justify their marketing campaigns, programs and tactics.

(C) 2005 Quark Technology Partnership. All rights reserved. Information in this document is subject to change without notice and does not represent a commitment on the part of Quark Technology Partnership or its licensee, Quark, Inc. Quark Products and materials are subject to the copyright and other intellectual property protection of the United States and foreign countries. Unauthorized use or reproduction without Quark's written consent is prohibited. Quark, the Quark logo and QuarkXPress are trademarks of Quark, Inc. and all applicable affiliated companies, Reg. US Pat. \& TM. Off. and in many other countries. Flash is a registered trademark of Macromedia, Inc. in the United States and/or other countries. All other marks are the properties of their respective owners. 